\title{
CONSERVATIVE MANAGEMENT OF TRAUMATIC BRAIN INJURY
}

\author{
Neha S. Jadhav ${ }^{1}$, Avinash S. $K^{2}$
}

${ }_{1}^{1}$ MCh Resident, Department of Neurosurgery, KEM, Mumbai, Maharashtra, India.

${ }^{2}$ Senior Resident, Department of General Surgery, GMCH, Miraj, Maharashtra, India.

\section{BACKGROUND}

ABSTRACT

Traumatic brain injuries are a major cause of morbidity and mortality in modern times and it is a huge health sector burden. [1] Understanding the mechanism of traumatic brain injury leads to the development of guidelines for the management of traumatic brain injury.

This study aims at evaluating the conservative management of traumatic brain injury.

\section{MATERIALS AND METHODS}

It is a retrospective and descriptive study conducted from January 2015 to December 2016 in the surgical department of our tertiary care hospital. 185 non-operated cases of traumatic brain injury were enrolled in the study.

\section{RESULTS}

The mean age was 29.84 years. The sex ratio was 6.4 . Road traffic accidents were responsible for injury in $82.16 \%$ of the cases. $48.65 \%$ of patients had a moderate brain injury (GCS 9 - 12), while 10.81\% had a severe brain injury (GCS 3 - 8). Radiological evaluation demonstrated the brain contusion in $48.65 \%$ of the cases. Prevention of post-traumatic seizure was done with the use of phenytoin. Mannitol was used for its osmotic properties to reduce cerebral oedema. Favourable outcome was noted in $56.75 \%$ of the cases. Common complications were lower respiratory tract complications, chronic neurological sequelae, urinary infection and hyponatremia. Mortality was recorded at $15.13 \%$.

\section{CONCLUSION}

Conservative management of traumatic brain injury involves use of the ventilatory assistance in all severe traumatic brain injuries, treatment of infectious complications and prevention of electrolyte imbalance.

\section{KEY WORDS}

Conservative Management. HOW TO CITE THIS ARTICLE: Jadhav NS, Avinash SK. Conservative management of traumatic brain injury. J. Evolution Med. Dent. Sci. 2018;7(36):3946-3949, DOI: 10.14260/jemds/2018/882

\section{BACKGROUND}

Traumatic brain injuries are a major cause of morbidity and mortality in modern times and it is a huge health sector burden.[1] Understanding the mechanism of traumatic brain injury lead to the development of guidelines for the management of traumatic brain injury.[2] The guidelines are in terms of both surgical and non-surgical management.

$50-60 \%$ of patients with Glasgow Coma Scale score of lesser or equal to 8 have one or more other organ systems injured. ${ }^{[3]} 25 \%$ have surgical lesions. There is $4-5 \%$ incidence of associated spine fractures with significant head injury (mostly C1 to C3).

\section{Brain Injury from Trauma Results from Two Distinct Processes-}

1. Primary Brain Injury: Occurs at the time of trauma (Cortical contusions, lacerations, bone fragmentation, diffuse axonal injury and brain stem contusion).

'Financial or Other Competing Interest': None.

Submission 09-08-2018, Peer Review 25-08-2018,

Acceptance 27-08-2018, Published 03-09-2018.

Corresponding Author:

Avinash S. K,

\#T1, Laxmivallabh Apartment, Mangalamurthy Colony,

Near Vasuade Hospital,

Near Reliance Market,

Sangli-416416, Maharashtra, India.

E-mail: avinashsk23@gmail.com

DOI: $10.14260 /$ jemds $/ 2018 / 882$

2. Secondary Brain Injury: Develops subsequent to the initial injury. Includes injury from intracranial haematomas, oedema, hypoxemia, ischaemia (primarily due to elevated intracranial pressure and/or shock)

The routine use of sedatives and paralytics in neurotrauma patients may lead to a higher incidence of pneumonia, longer ICU stays and possibly sepsis.[4] These agents also impair neurological assessment. $[5,6]$ Use, therefore should be reserved for cases with clinical evidence of intracranial hypertension, for intubation or where use is necessary for transport or to permit the evaluation of patient (eg: to get a combative patient to hold still for a CT scan).[7]

\section{Indications for Intubation in Traumatic Head Injury-}

1. Depressed level of consciousness: usually GCS less or equal to 7.

2. Need for hyperventilation.

3. Severe maxillofacial trauma.

4. Need for pharmacological paralysis for evaluation or management.

\section{Cautions Regarding Intubation-}

a. If a basal skull fracture through cribriform plate is possible, avoid nasotracheal intubation (to avoid intracranial entry of tube). In such cases use orotracheal intubation.

b. Prevents assessment of patient's ability to verbalise,[6] e.g. for determining Glasgow coma scale score. This 
ability should be noted (none, unintelligible, inappropriate, confused or oriented) prior to intubation.

c. Risk of lower respiratory tract infection.

Indications of Mannitol in Traumatic Head Injury Patients-

1. Evidence of intracranial hypertension.

a. Pupillary dilatation (Unilateral or bilateral).

b. Asymmetric pupillary reaction to light.

c. Decerebrate or decorticate posturing (Usually contralateral to fixed and dilated pupil).

d. Progressive deterioration of the neurologic exam, not attributable to extracranial factors.

2. Evidence of mass effect (Focal deficit, e.g. hemiparesis).

3. Sudden deterioration prior to CT (Including papillary dilatation).

4. After CT, if a lesion is associated with increased ICP is identified.

5. To assess salvageability: In patients with no evidence of brainstem function, look for return of brainstem reflexes.

\section{Contraindications to Mannitol Use-}

a. Prophylactic administration is not recommended due to its volume depleting effect. So it should be used only in appropriate indications.

b. Hypotension or Hypovolaemia: Hypotension can negatively influence outcome.[7] Therefore, when intracranial hypertension is present, first utilise sedation and/ or paralysis, and CSF drainage. If further measures are needed, fluid resuscitate the patient before administering mannitol. Use hyperventilation in hypovolaemic patients until mannitol can be given.

c. Relative contraindication: Mannitol may slightly impede normal coagulation.

d. Congestive Heart Failure: Before causing diuresis, mannitol transiently increases intravascular volume. So, use with caution in congestive heart failure may need to pre-treat with furosemide.

Routine use of Prophylactic Antiepileptic Drugs in Traumatic Brain Injury is Ineffective in preventing the Late Development of Post-traumatic Seizures and has been shown to be useful only in certain Circumstances. ${ }^{[8,9]}$

1. Acute subdural, epidural or intracerebral haematoma.

2. Open depressed skull fracture with parenchymal injury.

3. Seizure within the first $24 \mathrm{hrs}$. after injury.

4. Glasgow coma scale score $<10$.

5. Penetrating brain injury.

6. History of significant alcohol abuse.

7. Haemorrhagic contusion on CT.

Management of severe traumatic brain injury involves mechanical intubation, ventilator support and radiological assistance. Management of primary and secondary lesions require a multidisciplinary team made of anaesthetist, radiologist and neurosurgeons, nursing staff and physiotherapist.[10]

\section{MATERIALS AND METHODS}

This study is a retrospective descriptive study conducted from January 2015 to December 2016 at our tertiary care centre. 185 non-operated cases of traumatic brain injury were enrolled in the study.

\section{Inclusion Criteria}

Patients with traumatic brain injury admitted in our hospital were included in the study.

\section{Exclusion Criteria}

1. Cases in which the radiological data were absent were excluded from the study.

2. Multiple trauma cases that were operated for an associated lesion other than head trauma.

Clinical parameters, diagnosis, management and outcome of the management are evaluated. Data was collected from hospital register.

\section{RESULTS}

\section{Age and Sex}

The mean age was 28.76 years with extreme ranging from 3 to 85 years. There were total 160 men and 25 women and the sex ratio was 6.4 .

\section{Clinical Aspects}

\section{Predisposing Factors-}

1. Alcoholics

2. Diabetes

3. Hypertension

Among the predisposing factors, alcohol was the most common factor.

\section{Mode of Injury}

1. Road traffic accident 152 (82.16)

2. Assaults, falls

$33(17.84)$

Road traffic accident is by far the most common mode of injury.

Neurological Examination

Glasgow Coma Scale (GCS): Average GCS score was 11
a. $3-8$
$20(10.81)$
b. $9-12$
$90(48.65)$
c. $13-15$
$75(40.54)$

Seizures

$11(05.94)$

Neurological deficit

$21(13.51)$

\section{Related Injuries}

1. Thoracic $15(08.11)$

2. Cervical spine $12(06.48)$

3. Orthopaedic 21 (11.35)

Delay in admission- CT scan Average $=5$ days $(30$ minutes to 8 days). 


\begin{tabular}{|c|c|c|}
\hline $\begin{array}{c}\text { Radiological } \\
\text { Technique }\end{array}$ & $\begin{array}{c}\text { Number of } \\
\text { Patients }\end{array}$ & Percentage \\
\hline X-ray cervical spine & 90 & 48.64 \\
\hline X-ray chest & 72 & 38.92 \\
\hline X-ray base of skull & 7 & 3.78 \\
\hline CT brain plain & 165 & 89.19 \\
\hline MRI brain plain & 20 & 10.81 \\
\hline
\end{tabular}

\begin{tabular}{|c|c|c|}
\hline Findings & Number & Percentage \\
\hline Haemorrhagic Contusions & 90 & 48.64 \\
\hline Subarachnoid Haemorrhage & 33 & 17.84 \\
\hline Normal CT scan & 30 & 16.22 \\
\hline Acute Subdural Haematoma & 20 & 10.81 \\
\hline Pneumocephalus & 15 & 08.11 \\
\hline Extradural Haematoma & 10 & 05.41 \\
\hline Diffuse Cerebral Oedema & 06 & 03.24 \\
\hline \multicolumn{2}{|c|}{ Table 2. Findings on CT and MRI are as Follows } \\
\hline
\end{tabular}

When the CT scan was done, haemorrhagic contusion was the most common finding.

\section{Therapeutic Aspects}

The 20 cases of severe traumatic brain injury are managed by orotracheal intubation and ventilator support with sedation using midazolam. NSAIDS were used for analgesia. No tracheostomy was performed after the orotracheal intubation. Anti-epileptic treatment was administered in 11 cases who had convulsions; agent used was phenytoin. Immediate treatment of convulsion was the administration of the bolus of diazepam. The prophylaxis of post-traumatic seizure was used in 75 patients $(40.54 \%)$, the indications were cortical brain contusion, diffuse cerebral oedema, pneumocephalus, acute subdural haematoma, subarachnoid haemorrhage, extradural haematoma and GCS lesser or equal to 10 . We used phenytoin. Mannitol $20 \%$ was administered in all patients with severe traumatic brain injury. Intravenous proton-pump inhibitor was administered.

\section{Outcome}

Favourable outcome was noted in 105 patients (56.75\%) with a normal GCS, oral feeding and absence of neurological deficit. The average hospital stay for these patients was 6 days.

About 60 patients developed complications (32.43\%).

\begin{tabular}{|c|c|c|}
\hline Complications & Number & Percentage \\
\hline Lower respiratory tract infection & 29 & 48.33 \\
\hline Altered consciousness & 15 & 25.00 \\
\hline Urinary tract infection & 09 & 15.00 \\
\hline Hyponatremia & 07 & 11.66 \\
\hline Total & 60 & 100 \\
\hline \multicolumn{3}{|c|}{ Table 3. Types of Complications in our Study } \\
\hline
\end{tabular}

The average hospital stay for these patients with complication was 17 days.

28 patients of the series died $(15.13 \%)$ during the study period. Mortality was due to a complicated lower respiratory infection due to altered consciousness in 19 patients, 6 cases due to neurological problems, 3 cases due to electrolyte disturbance.

\section{DISCUSSION}

This was a retrospective study, so data collection was limited by difficulty in reaching patients who were discharged. In addition, there is influence of GCS in clinical evolution of patients. Alcohol is the most common predisposing factor and road traffic accident was the most common mode of injury. The management of severe brain trauma involves tracheal intubation and ventilatory support with continuous sedation.[10],[11] In our study, among the 20 patients admitted to intensive care, all were managed by intubation and ventilation. Sedation aims for cerebral protection and control of intracranial pressure and facilitation of care.[12,13] Prophylactic treatment of seizures was administered in 75 patients (40.54\%); post-traumatic seizures are classified according to time of occurrence[14] as immediate (within 24 hours), early (within a week) and late (over a week). Frequency of post-traumatic seizures is estimated between $5 \%$ and $7 \%$. It is related to the severity of the trauma $(11 \%)$ and mode of injury [eg. more with sharp object injuries].[15,16] Phenytoin is the preferred anti-epileptic for prophylactic treatment of seizures. In our study, drug used was phenytoin. Mannitol[17] was used for its osmotic properties to reduce cerebral oedema. The recommended dose is $50-100 \mathrm{mg} / \mathrm{kg}$ over 25 minutes. It improves cerebral perfusion pressure and microcirculation. However, its use is preferable when the blood-brain barrier is intact and it may predispose to hypotension or hypovolaemia, because of its volume depleting effect and it has to be used with caution in patients with congestive heart failure. The effects of hypertonic saline ${ }^{[18,19]}$ is comparable to mannitol, and it is more useful when haemorrhagic shock is associated with head injury. But it was not used in our study, because of lack of availability. Common complications were lower respiratory tract infections, more common with intubated patients.[20] Other common complications are electrolyte imbalance. Hyponatremia was the most common in our study (11.66\%), and would be related to salt wasting syndrome or syndrome of inappropriate antidiuretic hormone secretion. [21] Hospital mortality in traumatic brain injury is variable, ranges from $8.5 \%$ to $38 \% .[22],[23],[24]$ In our study, the mortality of $15.13 \%$ for deaths occurred during the study period. It is linked to neurological and infectious complications.

\section{CONCLUSION}

Among traumatic brain injuries, most injuries can be managed conservatively. Among intracranial lesions, cerebral contusions are predominant. Conservative management of brain injury involves prevention of secondary insult to brain which is usually of systemic origin, which in our study is respiratory complications followed by infection and electrolyte disturbances. The management of severe head trauma involves ventilatory assistance, prevention of posttraumatic seizures and the use of osmotic diuretics.

\section{REFERENCES}

[1] MacKenzie EJ, Siegal JH, Shapiro S, et al. Functional recovery and medical costs of trauma: an analysis by type and severity of injury. Journal of Trauma - Injury Infection \& Critical Care 1988;28(3):281-97. https://doi.org/10.1097/00005373-19880300000003 
[2] Brain Trauma Foundation, American Association of Neurological Surgeons, Congress of Neurological Surgeons. Guidelines for the management of severe traumatic brain injury. Journal of Neurotrauma 2007;24(Suppl 1):S1-S106.

https://doi.org/10.1089/neu.2007.9999

[3] Saul TG, Ducker TB. Effect of intracranial pressure monitoring and aggressive treatment on mortality in severe head injury. J Neurosurg 1982;56(4):498-503.

[4] Hsiang JK, Chesnut RM, Crisp CB, et al. Early routine paralysis for intracranial pressure control in severe head injury: Is it necessary? Crit Care Med 1994;22(9):1471-6.

[5] The Brain Trauma Foundation. The American Association of Neurological Surgeons. The Joint Section on Neurotrauma and Critical Care. Initial management. J Neurotrauma 2000;17(6-7):463-9.

[6] Marion DW, Carlier PM. Problems with initial Glasgow Coma Scale assessment caused by pre-hospital treatment of patients with head injuries: results of a national survey. J Trauma 1994;36(1):89-95.

[7] Bullock R, Chesnut RM, Clifton G, et al. Guidelines for the management of severe head injury. New York: Brain Trauma Foundation, 1995.

[8] Bullock R, Chesnut RM, Clifton G, et al. In: The role of antiseizure prophylaxis following head injury. Guidelines for the management of severe head injury. The Brain Trauma foundation (New York), The American Association of Neurological Surgeons (Park Ridge, Illinois) and The Joint Section of Neurotrauma and Critical Care, 1995.

[9] Chang BS, Lowenstein DH, Quality Standards Subcommittee of the American Academy of Neurology. Antiepileptic drug prophylaxis in severe traumatic brain injury: report of the Quality standards subcommittee of the American Academy of Neurology. Neurology 2003;60(1):10-6.

[10] Agence Nationale d'accréditation et d'évaluation en santé. Recommandations early management of severe traumatic brain injury. Guidelines for clinical practice. Annales Françaises d' Anesthésie et de Réanimation 1999;18:15-22. https://doi.org/10.1016/S0750-7658(99)80106-3

[11] Bouhours G, Minassian TA, Beydon L. Traumatismes crâniens graves: prise en charge à la phase initiale. Severe head injury: initial management. Réanimation 2006;15:552-60.

https://doi.org/10.1016/j.reaurg.2006.10.004

[12] Leone M, Visintini P, Alliez JR. et al. What sedation for prevention and treatment secondary brain insult? Annales Françaises d' Anesthésie et de Réanimation 2006;25:852-7.

https://doi.org/10.1016/j.annfar.2006.03.012
[13] Van Haverbeke L, Deraedt S, Thevenin-Lemoine B, et al. Severe head trauma in adults: early management in the île-de-France. Revue Med Ass Maladie 2004;35(1):19-25.

[14] Teasell R, Bayona N, Lippert C, et al. Post-traumatic seizure disorder following acquired brain injury. Brain Injury 2007;21(2):201-14. https://doi.org/10.1080/02699050701201854

[15] Yablon SA. Post-traumatic seizures. Archives of Physical Medicine and Rehabilitation 1993;74(9):9831001.

[16] The Brain Trauma Foundation. The American Association of Neurological Surgeons. The Joint Section on Neurotrauma and Critical Care. Role of antiseizure prophylaxis following head injury. Journal of Neurotrauma 2000;17(6-7):549-53. https://doi.org/10.1089/neu.2000.17.549

[17] Foster N, Engelhard K. Managing elevated intracranial pressure. Current Opinion in Anaesthesiology 2004;17(5):371-6. https://doi.org/10.1097/00001503-20041000000004

[18] Bayir H, Clark RS, Kochanek PM. Promising strategies to minimize secondary brain injury after brain trauma. Critical Care Medicine 2003;31(Suppl 1):112-7. https://doi.org/10.1097/00003246-20030100100016

[19] Piek J, Chesnut RM, Marshall LF, et al. Extracranial complications of severe head injury. Journal of Neurosurgery 1992;77(6):901-7.

https://doi.org/10.3171/jns.1992.77.6.0901

[20] Trouiller P, Mantz J. Early management of traumatic brain injury. La Lettre du Neurologue 2016;10:55-60.

[21] Fatigba OH, Padonou J. Epidemiology of traumatic brain injuries in Parakou (BENIN). African Journal of Neurological Sciences 2010;29:25-33.

[22] Emejulu JK. Epidemiological patterns of head injury in a newly established neurosurgical service: one-year prospective study. African Journal of Medicine and Medical Sciences 2008;37(4):383-8.

[23] Coulibaly Y, Dially, A, Fresner M, et al. Head trauma in the hospital du point g: About 80 Cases. Mali Médical 2004;19:3-4.

[24] Bahloul M, Chelly H, Ben Hmida M, et al. Prognosis of traumatic head injury in south Tunisia: a multivariate analysis of 437 cases. Journal of Trauma Injury Infection \& Critical Care 2004;57(2):255-61. https://doi.org/10.1097/01.TA.0000083004.35231.1 E 